\title{
The apparent clock-like evolution of Escherichia coli in glucose-limited chemostats is reproducible at large but not at small population sizes and can be explained with Monod kinetics
}

\author{
Lukas M. Wick,† Hansueli Weilenmann and Thomas Egli
}

Author for correspondence: Thomas Egli. Tel: +41 182351 58. Fax: +411 8235547.
e-mail: egli@eawag.ch

Swiss Federal Institute for Environmental Science and Technology, PO Box 611, Überlandstrasse 133, CH-8600 Dübendorf, Switzerland
To follow and model evolution of a microbial population in the chemostat, parameters are needed that give an indication of the absolute extent of evolution at a high resolution of time. In this study the evolution of the maximum specific growth rate $\left(\mu_{\max }\right)$ and the residual glucose concentration was followed for populations of Escherichia coli K-12 under glucose-limited conditions at dilution rates of $0.1 \mathrm{~h}^{-1}, 0.3 \mathrm{~h}^{-1}$ and $0.53 \mathrm{~h}^{-1}$ during 500-700 $\mathrm{h}$ in continuous culture. Whereas $\mu_{\max }$ improved only during the initial $150 \mathrm{~h}$, the residual glucose concentration decreased constantly during $500 \mathrm{~h}$ of cultivation and therefore served as a convenient parameter to monitor the evolution of a population at a high time resolution with respect to its affinity for the growthlimiting substrate. The evolution of residual glucose concentrations was reproducible in independent chemostats with a population size of $1^{11}$ cells, whereas no reproducibility was found in chemostats containing $10^{7}$ cells. A model based on Monod kinetics assuming successive take-overs of mutants with improved kinetic parameters (primarily $K_{\mathrm{s}}$ ) was able to simulate the experimentally observed evolution of residual glucose concentrations. Similar values for the increase in glucose affinity of mutant phenotypes $\left(K_{\mathrm{s} \text { (mutant) }} \cong 0.6 \times K_{\mathrm{s} \text { (parent) }}\right)$ and similar mutation rates per cell per generation leading to these mutant phenotypes $\left(1-5 \times 10^{-7}\right)$ were estimated in silico for all dilution rates. The model predicts a maximum rate of evolution at a dilution rate slightly below $\mu_{\max } / 2$. With increasing and decreasing dilution rates the evolution slows down, which also explains why in special cases a selectiondriven evolution can exhibit apparent clock-like behaviour. The glucose affinity for WT cells was dependent on the dilution rate with highest values at dilution rates around $\mu_{\text {max }} / 2$. Below $0.3 \mathrm{~h}^{-1}$ poorer affinity was mainly due to the effects of rpos.

Keywords: continuous culture, maximum specific growth rate, glucose affinity, molecular clock, rpoS

\section{INTRODUCTION}

Bacteria grown in chemostats are evolving constantly. In fact, Novick \& Szilard (1950), soon after having invented the chemostat, recognized that the observed

†Present address: Microbial Evolution Laboratory, National Food Safety and Toxicology Center, Michigan State University, East Lansing, MI 48824, USA. shifts in frequency of neutral mutations, such as T5 resistance, are a manifestation of evolution. Mutants with increased fitness arise periodically in chemostat and batch cultures, which results in a replacement of the original population, a phenomenon referred to as periodic selection (Atwood et al., 1951; Dykhuizen, 1990). Theoretical considerations suggested that for populations where the product of cell number and mutation rate (referred to here as the number of 
advantageous mutations per cell and per generation) is much higher than one, the effects of selection can be described by deterministic equations and therefore should be reproducible (Dykhuizen, 1990; Kubitschek, 1974; Wahl \& Krakauer, 2000). However, experimental data supporting these assumptions are scarce, especially because a high time resolution is needed to demonstrate the degree of reproducibility of the evolution in parallel populations.

Dykhuizen and Hartl (Dykhuizen \& Hartl, 1981; Hartl \& Dykhuizen, 1979) compared the evolution of the competitive ability of Escherichia coli populations in glucose-limited continuous culture at dilution (growth) rates of $0 \cdot 14 \mathrm{~h}^{-1}$ and $0 \cdot 28 \mathrm{~h}^{-1}$, corresponding to generation times of 5 and $2.5 \mathrm{~h}$, respectively. Over a period of $500 \mathrm{~h}$ they removed samples from the continuous culture every $100 \mathrm{~h}$, determined the $\mu_{\max }$ (maximum specific growth rate) and competed each population with the population isolated $100 \mathrm{~h}$ earlier. Whereas $\mu_{\max }$ increased during the first $100 \mathrm{~h}$ and then remained constant, an increase in glucose affinity was observed over the whole $500 \mathrm{~h}$ period. Surprisingly, the increase in glucose affinity did not proceed faster in the population with the shorter generation time. In fact, the evolution of the two populations was dependent on the absolute time rather than on the number of generations. This observation was reminiscent of the molecular clock, i.e. that the substitution rates of amino acids in a given protein are fairly constant over time for different species. However, such a molecular clock was proposed to hold only when the amino acid substitutions are selectively neutral (Ayala, 2000; Kimura, 1983; Zuckerkandl \& Pauling, 1965). A rationale or even a model explaining why in the case of the Dykhuizen-Hartl experiment a selection driven evolution exhibited an apparent clocklike behaviour was not given.

Different models have been proposed to describe the growth kinetics of a microbial population growing with a single limiting substrate. Statistical analysis by Senn et al. (1994) has shown that out of several tested models, the three models of Monod (1942), Shehata \& Marr (1971) and Westerhoff et al. (1982) described their experimental data equally well. The Monod model describes the relationship between $\mu$ and $s$ (substrate concentration) by a type of saturation kinetics:

$\mu=\mu_{\max } \frac{s}{K_{\mathrm{s}}+s}$

where $\mu$ is the specific growth rate, $\mu_{\max }$ the maximum specific growth rate at saturating substrate concentrations, $s$ the substrate concentration and $K_{\mathrm{s}}$ the substrate affinity, i.e. the substrate concentration at which the cells grow at half maximum specific growth rate. The clear advantage of the Monod model is that the parameters $\mu, \mu_{\max }, s$ and $K_{\mathrm{s}}$ have a biological meaning and are experimentally accessible. A weakness of the original Monod model is that it neglects the concept of maintenance energy, which implies a substrate flux even at a specific growth rate of $0 \mathrm{~h}^{-1}$. Different models have been proposed to solve this problem (Kovářová, 1996; Pirt, 1965; Powell, 1967; Westerhoff et al., 1982). The extended Monod model of Kovárová (Equation 2) includes an $s_{\min }$ term, which denotes the minimal substrate concentration needed for growth:

$\mu=\mu_{\max } \frac{s-s_{\min }}{K_{\mathrm{s}}+s-s_{\min }}$

This model provides a good fit for data obtained for steady-state glucose concentrations in cultures of E. coli cultivated in glucose-limited chemostats at different temperatures and dilution rates (Kovářová et al., 1996).

To follow and model evolution of a microbial population in the chemostat, we need one or more parameters that give an indication of the absolute extent of evolution. Such parameters should be measurable without much labour to obtain a high time resolution of the evolutionary process. In our case the parameter $s$ of the Monod model exhibits these characteristics. Monod $K_{\mathrm{s}}$ values calculated from residual glucose concentrations have shown that populations of E. coli ML 30 (Kovářová-Kovar \& Egli, 1998; Senn et al., 1994) and E. coli K-12 (Wick et al., 2001) improve their glucose affinity during growth under glucose-limited conditions. In this work we monitored the Monod parameters $\mu_{\max }$ and $s$ of E. coli K-12 during growth for $500-700 \mathrm{~h}$ in glucose-limited chemostats at dilution rates of $0 \cdot 1 \mathrm{~h}^{-1}$, $0.3 \mathrm{~h}^{-1}$ and $0.53 \mathrm{~h}^{-1}$. Using the extended Monod model we modelled periodic take-overs of the culture by mutant populations with improved glucose affinity. Such periodic take-overs lead to a steady decrease in residual glucose concentration in a continuous culture. By fitting calculated $s$ values to the measured ones we inferred the improved $K_{\mathrm{s}}$ values of the modelled mutant populations and mutation rates (i.e., advantageous mutations per cell per generation) leading to these improved $K_{\mathrm{s}}$ values. The Monod model showed that in special cases, populations of cells cultivated at longer generation times can evolve as quickly as populations of cells grown at shorter generation times. This is because a stronger selection pressure per generation can compensate for fewer generations per time interval. The model proposed here can explain the apparent clock-like behaviour of the selection-driven evolution described previously (Dykhuizen \& Hartl, 1981; Hartl \& Dykhuizen, 1979).

\section{METHODS}

Bacterial strains and growth conditions. Wild-type Escherichia coli K-12 MG 1655, and cultivation conditions for batch and large bioreactors were the same as described previously (Wick et al., 2001). An rpoS negative derivative of the WT was constructed by P1 transduction (Miller, 1972) of the rpoS13:: Tn10 allele from strain E. coli MV2792 (Volkert et al., 1994) to E. coli K-12 MG 1655. Successful transduction resulted in tetracycline resistant cells with decreased catalase activity as seen in reduced bubbling of the cells when exposed to hydrogen peroxide (Sak et al., 1989).

The glucose-limited medium supported a $\mu_{\max }( \pm \mathrm{SD})$ of $0.63 \pm 0.01 \mathrm{~h}^{-1}(n=14)$ for the wild-type strain. At $0.65 \pm$ $0.01 \bar{h}^{-1}(n=7)$, the growth rate for the rpoS strain was 
Table 1. Parameters and variables used in this communication

\begin{tabular}{|c|c|}
\hline Abbreviation & Definition \\
\hline$D$ & $\begin{array}{l}\text { Dilution rate of a chemostat }\left(\mathrm{h}^{-1}\right) \text {; equal to the specific growth rate }(\mu) \text { of cells in } \\
\text { the chemostat at steady state }\end{array}$ \\
\hline$D_{\text {min }}$ & $\begin{array}{l}\text { Dilution rate at which selection of mutants with a given improved } K_{\mathrm{s}} \text { is predicted } \\
\text { to occur fastest in respect to absolute time }\left(\mathrm{h}^{-1}\right)\end{array}$ \\
\hline$F_{\mathrm{i}}$ & $\begin{array}{l}\text { Improvement factor of } K_{\mathrm{s}} \text { per mutation: quotient of the } K_{\mathrm{s}} \text { value of a phenotype } \\
\text { divided by the } K_{\mathrm{s}} \text { value of its parent phenotype }\end{array}$ \\
\hline$K_{\mathrm{s}}$ & $\begin{array}{l}\text { Substrate affinity; i.e. substrate concentration that allows cells to grow at } \\
\mu_{\max } / 2\left(\mu \mathrm{g} \mathrm{l}^{-1}\right)\end{array}$ \\
\hline$K_{\mathrm{s}, \mathrm{i}}$ & $\begin{array}{l}\text { Substrate affinity of phenotype } \mathrm{i} \text {; i.e. substrate concentration that allows cells of } \\
\text { phenotype } i \text { to grow at } \mu_{\max , \mathrm{i}} / 2\left(\mu \mathrm{g} \mathrm{l^{-1 }}\right)\end{array}$ \\
\hline$m r$ & Mutation rate: advantageous mutations per cell per generation \\
\hline$s$ & Substrate concentration in the chemostat $\left(\mu \mathrm{g} \mathrm{l}^{-1}\right)$ \\
\hline$s_{0}$ & Substrate concentration in the medium feed $\left(\mu \mathrm{g} \mathrm{l}^{-1}\right)$ \\
\hline$s_{\min }$ & Minimum substrate concentration that supports growth $\left[(12 \pm 2) \mu \mathrm{g} \mathrm{l}^{-1}\right]$ \\
\hline$S_{\mathrm{g}}$ & Selection coefficient per generation, as defined in Equation 7 \\
\hline$S_{\mathrm{h}}$ & Selection coefficient per hour, as defined in Equation 6 \\
\hline$t$ & Time $(\mathrm{h})$ \\
\hline$V$ & Rate of glucose uptake [ng $\mathrm{min}^{-1}\left(10^{8} \text { cells }\right)^{-1}$ ] \\
\hline$V_{\max }$ & Maximum rate of glucose uptake $\left[\mathrm{ng} \min ^{-1}\left(10^{8} \text { cells }\right)^{-1}\right.$ ] \\
\hline$X_{\mathrm{i}}$ & Total number of bacteria of phenotype $i$ in the chemostat \\
\hline Y & Yield of cells on glucose $\left(10^{6} \mu \mathrm{g}^{-1}\right)$ \\
\hline$\mu$ & Specific growth rate $\left(\mathrm{h}^{-1}\right)$ \\
\hline$\mu_{\max }$ & Maximum specific growth rate $\left(\mathrm{h}^{-1}\right)$ \\
\hline$\mu_{\max , \mathrm{i}}$ & Maximum specific growth rate of phenotype $i\left(\mathrm{~h}^{-1}\right)$ \\
\hline
\end{tabular}

significantly higher $(P=0 \cdot 001, t$-test $)$. The parameters and variables used are shown in Table 1.

Small chemostats were self-assembled from Schott flasks and had a working volume of $75 \mathrm{ml}$. Stirring was achieved by a standard laboratory magnetic stirrer. Air was not introduced into the culture directly as in large cultures but only into the headspace. The $\mathrm{pH}$ was buffered at $\mathrm{pH} 7$ with $\mathrm{Na}_{2} \mathrm{HPO}_{4} /$ $\mathrm{KH}_{2} \mathrm{PO}_{4}(14.4 \mathrm{mM} / 4.4 \mathrm{mM})$. The chemostats were inoculated with approximately $5 \times 10^{6}$ cells and the medium flow (containing $1 \mathrm{mg}$ glucose $\mathrm{l}^{-1}$; note that the medium in large chemostats contained $100 \mathrm{mg}$ glucose $\mathrm{l}^{-1}$ ) was started immediately at $0 \cdot 3 \mathrm{~h}^{-1}$. The total cell number $( \pm \mathrm{SD})$ in small chemostats, assessed by plate counts, was $(3 \pm 2) \times 10^{7}$ $(n=20)$; the total cell number in large chemostats at $0.3 \mathrm{~h}^{-1}$, assessed by plate counts, was $(9 \pm 4) \times 10^{10}(n=6)$.

Determination of maximum specific growth rates. Cells taken from the chemostat were transferred to shake flasks containing glucose minimal medium, where the specific growth rate increased gradually. Cells were always transferred to a fresh batch culture before they reached the late exponential phase. Maximum specific growth rates were determined after the specific growth rate became constant. This was the case after about 3,5 and $12 \mathrm{~h}$ for cells taken from chemostats operated at $0.53 \mathrm{~h}^{-1}, 0.3 \mathrm{~h}^{-1}$ and $0 \cdot 1 \mathrm{~h}^{-1}$, respectively. The $\mathrm{OD}_{546}$ values of the batch cultures were determined every $20 \mathrm{~min}$ as long as their $\mathrm{OD}_{546}$ was between $0 \cdot 08$ and $0 \cdot 5$. The natural logarithms of these $\mathrm{OD}_{546}$ values were plotted against time and the slope of the resulting linear regression line was taken as $\mu_{\max }$. The values obtained for $\mu_{\max }$ were highly reproducible (see Table 2)

Glucose analysis. Glucose concentrations in continuous cultures were determined as described previously by Senn et al. (1994).
Glucose uptake assays. Cells $(30 \mathrm{ml})$ from the continuous cultures were collected by centrifugation for $10 \mathrm{~min}$ at $1200 \mathrm{~g}$ at $4{ }^{\circ} \mathrm{C}$, washed twice with buffer (glucose-free medium) and resuspended to an $\mathrm{OD}_{546}$ of 10 . For the assays, cells were diluted to an appropriate cell density $\left(\mathrm{OD}_{546}\right.$ between $0 \cdot 1$ and $0.005)$, dependent on the glucose concentration in the assay, so that the uptake was in a linear range during the first 2 to 3 min. The assays were performed at $37^{\circ} \mathrm{C}$ and were started by adding $80 \mu \mathrm{l}\left[{ }^{14} \mathrm{C}\right]$ glucose to $720 \mu \mathrm{l}$ bacterial suspension. Final glucose concentrations were 40, 10, 4, 2, 1, 0.5, 0.25, 0.125 and $0.0625 \mu \mathrm{M}$. Samples $(100 \mu \mathrm{l})$ were removed at 20, 40, 60, 90, 120 and $150 \mathrm{~s}$, immediately filtered through $0.45 \mu \mathrm{m}$ cellulose nitrate membrane filters (Millipore) and washed with $10 \mathrm{ml}$ buffer. The filters were dissolved in scintillation liquid (Filter count, Packard Instruments) and the radioactivity was determined with a BETAmatic I liquid scintillation counter (Kontron Analytical). $K_{\mathrm{s}}$ and $V_{\max }$ values were determined by the direct linear plot method (Eisenthal \& Cornish-Bowden, 1974). In contrast to the original method, we did not determine the coordinates of intersections graphically, but we calculated them from their linear equations.

Modelling. For mathematical calculations and modelling the program AQUASIM was used (Reichert, 1994). The Monod equation was the basis for the modelling of the time-dependent substrate and cell concentrations in the reactor (Monod, 1942). Instead of the classic Monod model, a modified equation including an $s_{\min }$ term was employed (Kovárová et al., 1996):

$\mu=D=\mu_{\max } \frac{s-s_{\min }}{K_{\mathrm{s}}+s-s_{\min }}$

Based on this equation the following differential equations 
Table 2. Parameters of predicted mutant phenotypes in E. coli populations evolving at different dilution rates

All $\mu_{\max }$ values and the $K_{\mathrm{s}}$ values of WT at $0.3 \mathrm{~h}^{-1}$ and $0.53 \mathrm{~h}^{-1}$ were determined experimentally, whereas in a simultaneous fit all other $K_{\mathrm{s}}$ values, mutation rates and their standard errors were inferred using the computer program AQUASIM. Standard errors of $K_{\mathrm{s}}$ were estimated without considering the deviations of $\mu_{\max }$, since these were very small.

\begin{tabular}{|c|c|c|c|c|c|c|c|c|c|}
\hline & \multicolumn{3}{|c|}{$0 \cdot 1 \mathrm{~h}^{-1}$} & \multicolumn{3}{|c|}{$0 \cdot 3 \mathrm{~h}^{-1}$} & \multicolumn{3}{|c|}{$0.53 \mathrm{~h}^{-1}$} \\
\hline & $\boldsymbol{K}_{\mathrm{s}}^{*}( \pm \mathrm{SE})$ & $\mu_{\max } \dagger( \pm \mathrm{SD})$ & $F_{\mathrm{i}} \neq$ & $\boldsymbol{K}_{\mathrm{s}}^{*}( \pm \mathrm{SE})$ & $\mu_{\max } \dagger( \pm S D)$ & $F_{\mathrm{i}} \neq$ & $\boldsymbol{K}_{\mathrm{s}}^{*}( \pm \mathrm{SE})$ & $\mu_{\max } \dagger( \pm S D)$ & $F_{\mathrm{i}} \neq$ \\
\hline WT & $828 \pm 97$ & $0 \cdot 63 \pm 0 \cdot 01$ & & $366 \pm 4$ & $0 \cdot 63 \pm 0 \cdot 01$ & & $560 \pm 27$ & $0 \cdot 63 \pm 0 \cdot 01$ & \\
\hline Phenotype 1 & $202 \pm 14$ & $0 \cdot 67 \pm 0 \cdot 01$ & $0 \cdot 24$ & $241 \pm 4$ & $0.73 \pm 0 \cdot 01$ & $0 \cdot 66$ & $422 \pm 18$ & $0 \cdot 78 \pm 0 \cdot 01$ & 0.75 \\
\hline Phenotype 2 & $108 \pm 11$ & $0 \cdot 67 \pm 0.01$ & $0 \cdot 53$ & $129 \pm 3$ & $0 \cdot 73 \pm 0 \cdot 01$ & 0.53 & $274 \pm 11$ & $0 \cdot 78 \pm 0 \cdot 01$ & 0.65 \\
\hline Phenotype 3 & $63 \pm 7$ & $0 \cdot 67 \pm 0 \cdot 01$ & $0 \cdot 58$ & $83 \pm 3$ & $0 \cdot 73 \pm 0 \cdot 01$ & $0 \cdot 64$ & $158 \pm 6$ & $0 \cdot 78 \pm 0 \cdot 01$ & $0 \cdot 58$ \\
\hline Phenotype 4 & $41 \pm 5$ & $0 \cdot 67 \pm 0 \cdot 01$ & $0 \cdot 65$ & $46 \pm 2$ & $0.73 \pm 0 \cdot 01$ & $0 \cdot 55$ & $111 \pm 5$ & $0 \cdot 78 \pm 0 \cdot 01$ & $0 \cdot 7$ \\
\hline Phenotype 5 & & & & & & & $76 \pm 3$ & $0 \cdot 78 \pm 0.01$ & 0.68 \\
\hline $\begin{array}{l}\text { Mean } F_{\mathrm{i}} \\
m r \|( \pm \mathrm{SE})\end{array}$ & & $(5 \cdot 3 \pm 4 \cdot 5) \times 10^{-7}$ & $0.5 / 0.59 \mathbb{S}$ & & $(1 \cdot 1 \pm 0 \cdot 2) \times 10^{-7}$ & $0 \cdot 6$ & & $(5 \cdot 3 \pm 1 \cdot 3) \times 10^{-7}$ & 0.67 \\
\hline Sample size & $103(s)$ & $9\left(\mu_{\max }\right)$ & & $171(s)$ & $6\left(\mu_{\max }\right)$ & & $69(s)$ & $10\left(\mu_{\max }\right)$ & \\
\hline
\end{tabular}

$* \mu \mathrm{g} \mathrm{l^{-1 }}$.

$\dagger h^{-1}$.

$\ddagger F_{\mathrm{i}}$, the improvement factor of $K_{\mathrm{s}}$ per mutation is defined as the quotient of the $K_{\mathrm{s}}$ value of a phenotype divided by the $K_{\mathrm{s}}$ value of its parent phenotype.

$\$$ Mean $F_{i}$ value of phenotype $1 / 2$ to phenotype $4 / 5$.

$\|$ Advantageous mutations per cell per generation.

I No. measured residual glucose concentrations used to infer $K_{\mathrm{s}}$ values and mutation rates $(s)$ and number of measurements made to determine the $\mu_{\max }$ of evolved phenotypes $\left(\mu_{\max }\right)$.

were used to describe the dynamics of cell growth, washout, mutant generation and substrate concentration for all $i$ phenotypes in the continuous culture where phenotype $i$ is created from phenotype $i-1$ by mutation (the last term of Equation 4; this term is only considered if $\left.X_{\mathrm{i}-1}(t)>1 / m r\right)$ :

$$
\begin{aligned}
\frac{d X_{\mathrm{i}}}{d t}=-D X_{\mathrm{i}}(t)+\mu_{\mathrm{max}, \mathrm{i}} \frac{s(t)-s_{\min }}{K_{\mathrm{s}, \mathrm{i}}+s(t)-s_{\min }} X_{\mathrm{i}}(t)+ \\
\mu_{\max , \mathrm{i}-1} \frac{s(t)-s_{\min }}{K_{\mathrm{s}, \mathrm{i}-1}+s(t)-s_{\min }} X_{\mathrm{i}-1}(t) m r
\end{aligned}
$$$$
\frac{d s}{d t}=s_{0} D-s(t) D-\mu_{\max , \mathrm{i}} \frac{s(t)-s_{\min }}{K_{\mathrm{s}, \mathrm{i}}+s(t)-s_{\min }} X_{\mathrm{i}}(t) \frac{1}{Y}
$$

Values for $\mu_{\max }$ and $s$ were determined experimentally. With the parameter estimation tool of AQUASIM we inferred $K_{\mathrm{s}, i}$ values of mutant phenotypes, which were supposed to periodically take over the population. Simultaneous with the $K_{\mathrm{s}}$ values, the mutation rates $(\mathrm{mr})$ leading to those mutant phenotypes, and the correlation coefficients of the $K_{\mathrm{s}}$ and $m r$ values were inferred by AQUASIM. A weighted least squares parameter estimation was performed for $K_{\mathrm{s}, \mathrm{i}}$ and $m r$ by fitting calculated $s$ values $\left(s_{\text {pred }}\right)$ to measured $s$ values $\left(s_{\text {obs }}\right)$. This was done by minimizing $\chi^{2}$ values using the secant method, where $\chi^{2}=\sum\left[\left(s_{\text {obs }}-s_{\text {pred }}\right) / \mathrm{SD}\right]^{2}$ and SD denotes the estimated standard deviations of the measured $s$ values. SD values for $s$ values were estimated from deviations of measured $s$ values to be $10 \%$. However, values from the first $100 \mathrm{~h}$ of chemostats run at higher dilution rates $\left(\geqslant 0.5 \mathrm{~h}^{-1}\right)$ showed higher deviations and SD was estimated to be $20 \%$. For $s$ values measured during the first $75 \mathrm{~h}$ in $0 \cdot 1 \mathrm{~h}^{-1}$ chemostats the SD values were set to $30 \%$ instead of $10 \%$. This was done because a chemostat population needs about 5-10 volume changes $(50-100 \mathrm{~h}$ at $0 \cdot 1 \mathrm{~h}^{-1}$ ) to reach a steady state, which probably also leads to variations in residual glucose concentrations. Since the model does not take into account this physiological adaptation, the difference between modelled and measured values was allowed to be higher for values taken during this period (see also 'Model' Results section).

\section{RESULTS}

\section{Evolution of kinetic parameters during glucose-limited chemostat growth}

Chemostats with E. coli populations were set up and run under glucose-limited conditions for 500-700 h at different dilution rates. The evolution of the residual glucose concentration, $\mu_{\max }$ values and $K_{\mathrm{s}}$ towards glucose was monitored.

Residual glucose concentrations were measured for four chemostats at $0.3 \mathrm{~h}^{-1}$, three at $0.1 \mathrm{~h}^{-1}$ and one at $0.53 \mathrm{~h}^{-1}$. All these chemostats were inoculated with different single clones from the same glycerol stock culture. The time-course of evolution between independent runs was highly reproducible (Fig. 1).

At all dilution rates, $\mu_{\max }$ increased in the first $50-150 \mathrm{~h}$; the increase was faster for $0.1 \mathrm{~h}^{-1}$ and $0.53 \mathrm{~h}^{-1}$ than for $0 \cdot 3 \mathrm{~h}^{-1}$. Later, between 150 and $500 \mathrm{~h}$ of cultivation the 

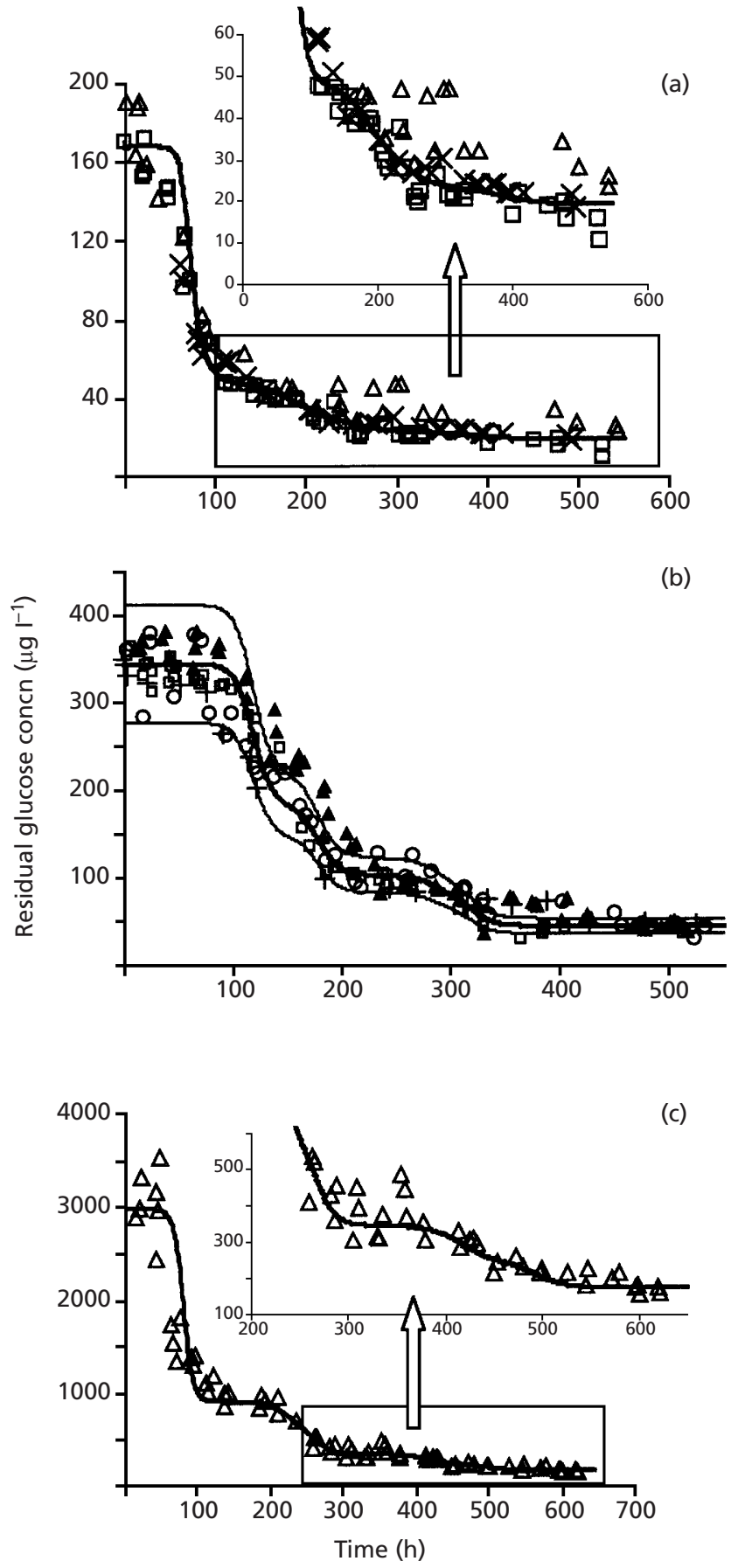

Fig. 1. Evolution of the residual glucose concentration in glucose-limited chemostats of $E$. coli $\mathrm{K}-12$ run at dilution rates of $0.1 \mathrm{~h}^{-1}$ (a), $0.3 \mathrm{~h}^{-1}$ (b) and $0.53 \mathrm{~h}^{-1}$ (c). Experimental data from independent cultures (different symbols) and model predictions (thick lines) are shown. Measured values in (b) are from Wick et al. (2001). The predicted glucose concentrations were calculated using AQUASIM with inferred $K_{\mathrm{s}}$ values and mutation rates that provided the best fit to the measured glucose concentrations. These parameters are listed in Table 2. The insets show a magnification of the boxed areas. For a culture that would evolve exactly as predicted (thick line) the $95 \%$ confidence interval of measured values is given by thinner lines in (b), under the assumption that the standard deviation of glucose measurements is $10 \%$.

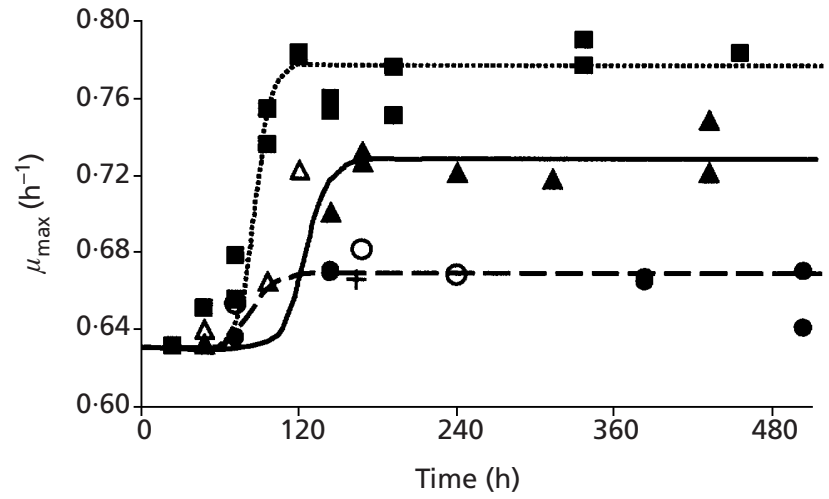

Fig. 2. Evolution of $\mu_{\max }$ in glucose-limited chemostats of $E$. coli $\mathrm{K}-12$ run at different dilution rates. Experimental data (symbols) and model predictions (lines) are shown for $0.1 \mathrm{~h}^{-1}$ $(0,0,+$, dashed line $), 0.3 \mathrm{~h}^{-1}\left(\triangle, \boldsymbol{\Delta}\right.$, solid line) and $0.53 \mathrm{~h}^{-1}$ ( $\boldsymbol{\square}$, dotted line). The predicted values were calculated using AQUASIM with the kinetic parameters listed in Table 2.

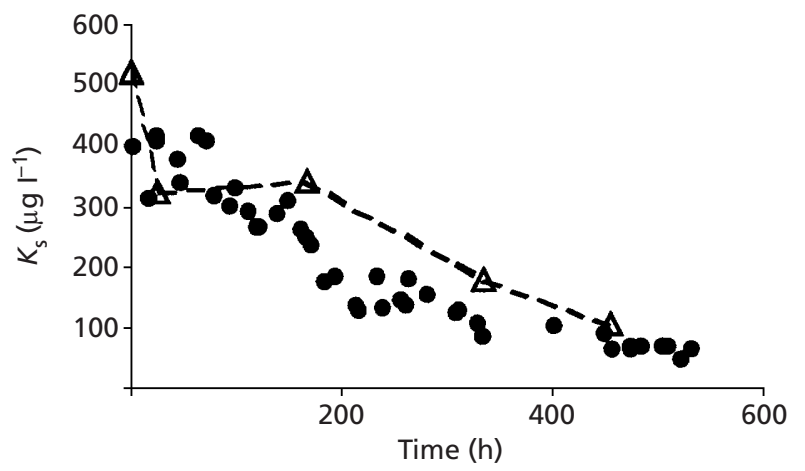

Fig. 3. Comparison of $K_{\mathrm{s}}$ values for glucose determined by uptake assays with $\left[{ }^{14} \mathrm{C}\right]$ glucose $(\triangle)$ and by calculation from residual glucose concentration ( $(\mathbf{O})$ during evolution of a culture of $E$. coli K-12 in a glucose-limited chemostat run at $D=0.3 \mathrm{~h}^{-1}$.

$\mu_{\max }$ remained constant (Fig. 2). Improved $\mu_{\max }$ values were calculated as mean values of the measurements taken at time points after the initial steep increase ( $>120 \mathrm{~h}$ for $0 \cdot 1 \mathrm{~h}^{-1},>150 \mathrm{~h}$ for $0 \cdot 3 \mathrm{~h}^{-1}$ and $>120 \mathrm{~h}$ for $\left.0.53 \mathrm{~h}^{-1}\right)$. The means and standard deviations of these measurements were $0.67 \pm 0.01 \mathrm{~h}^{-1} \quad(n=9)$ for cells evolved at $0 \cdot 1 \mathrm{~h}^{-1}, 0 \cdot 73 \pm 0 \cdot 01 \mathrm{~h}^{-1}(n=6)$ for cells evolved at $0.3 \mathrm{~h}^{-1}$ and $0 \cdot 78 \pm 0 \cdot 01 \mathrm{~h}^{-1}(n=10)$ for cells evolved at $0.53 \mathrm{~h}^{-1}$. The $\mu_{\max }$ of cells evolved at $0 \cdot 1 \mathrm{~h}^{-1}$ was significantly higher than the $\mu_{\max }$ of the WT cells $\left(P=2 \times 10^{-7}, t\right.$-test $)$, the $\mu_{\max }$ of cells evolved at $0 \cdot 3 \mathrm{~h}^{-1}$ was significantly higher than that of cells evolved at $0 \cdot 1 \mathrm{~h}^{-1}\left(P=6 \times 10^{-7}, t\right.$-test $)$ and the $\mu_{\max }$ of cells evolved at $0.53 \mathrm{~h}^{-1}$ was significantly higher than that of cells evolved at $0 \cdot 3 \mathrm{~h}^{-1}\left(P=9 \times 10^{-6}, t\right.$-test $)$.

The Monod model implies that $K_{\mathrm{s}}$ can be calculated from measured $\mu_{\max }$ and residual glucose concentrations. Another classical method to determine $K_{\mathrm{s}}$ for a 


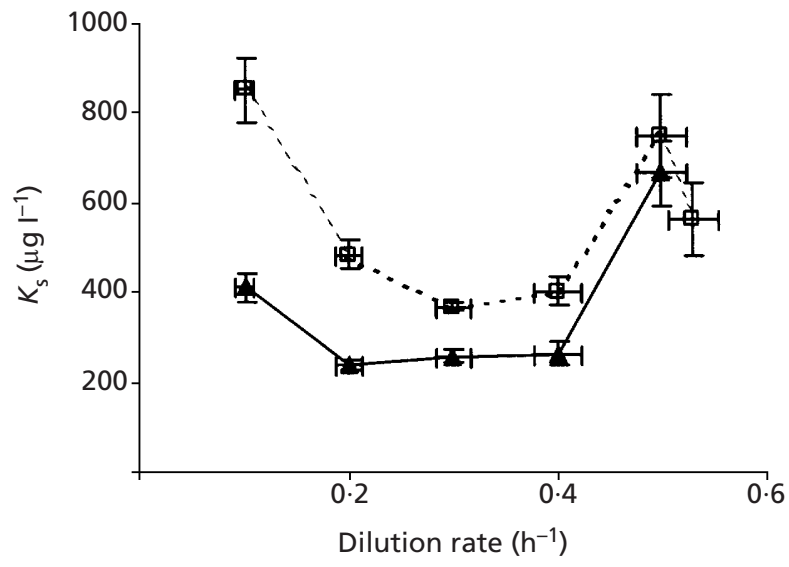

Fig. 4. $K_{\mathrm{s}}$ values of $E$. coli $\mathrm{K}-12 \mathrm{WT}(\square)$ and of its rpoS negative derivative $(\boldsymbol{\Delta}) . K_{\mathrm{s}}$ values at different dilution rates were determined from residual glucose concentrations measured in chemostats inoculated with fresh cells. For calculation of $K_{\mathrm{s}}$ glucose concentrations were taken only from the initial phase before they started to decrease. Error bars represent $95 \%$ confidence intervals. Intervals for $K_{\mathrm{s}}$ are given as $t$ intervals. Deviations of $\mu_{\max }$ and $s_{\min }$ were taken into consideration for the calculation of the error bars. The degrees of freedom were $7,7,40,6,3$ and 6 for experiments with WT cells in $0.1,0.2,0.3$, $0.4,0.5$ and $0.53 \mathrm{~h}^{-1}$ chemostats, respectively, and $12,9,14,10$ and 12 for rpos cells in $0.1,0.2,0.3,0.4$ and $0.5 \mathrm{~h}^{-1}$ chemostats, respectively. Intervals for $D$ were calculated from estimated standard deviations of the parameters determining $D(D=$ flow rate/reactor volume).

particular substrate is to measure the uptake rate $(V)$ of the substrate in dependence of the substrate concentration $(s) . K_{\mathrm{s}}$ and $V_{\max }$ are then calculated by the direct linear plot method described by Eisenthal \& CornishBowden (1974). At different time points $K_{\mathrm{s}}$ values of an E. coli population growing at $0 \cdot 3 \mathrm{~h}^{-1}$ were determined by both methods (Fig. 3). The two methods gave similar results, the correlation coefficient being $0.89(P=0 \cdot 043)$.

\section{Growth rate dependence of initial glucose affinity in continuous culture}

$K_{\mathrm{s}}$ values calculated from the initial residual glucose concentrations from chemostats operated at dilution rates of $0.1 \mathrm{~h}^{-1}, 0.3 \mathrm{~h}^{-1}$ and $0.53 \mathrm{~h}^{-1}$ (Fig. 1) indicated a growth rate dependence of $K_{\mathrm{s}}$. Since the level of the general stress response regulator $\mathrm{RpoS}$ is inversely related to growth rate (Lange \& Hengge-Aronis, 1994; Notley \& Ferenci, 1996) and RpoS-attenuated strains exhibit a growth advantage in stationary phase (Zambrano et al., 1993), the influence of $r p o S$ on initial $K_{\mathrm{s}}$ values was assessed using an rpoS negative mutant. Continuous cultures were set up at different dilution rates, each inoculated with cells from batch cultures as described in Methods. Residual glucose concentrations were measured during the first $50 \mathrm{~h}$ of cultivation. $K_{\mathrm{s}}$ values were calculated from residual glucose concentrations before they started to decrease. The $K_{\mathrm{s}}$ values as a function of dilution rate for the WT and $r p o S$ strain are shown in Fig. 4.

\section{Model}

The decrease of the residual glucose concentration suggests that mutant phenotypes with increased glucose affinity periodically take over the chemostat population. Some of the important questions immediately arising are now : how much do the $K_{\mathrm{s}}$ values improve at each takeover and what is the rate at which advantageous mutations arise per cell and generation? We used the kinetic simulation program AQUASIM to give estimations for these values. The following assumptions were made for the simulation. (i) The growth of the bacteria in the chemostat can be described with extended Monod kinetics (Kovářová et al., 1996). (ii) The chemostat is inoculated with a WT strain with given $\mu_{\max }\left(0.63 \mathrm{~h}^{-1}\right)$ and $K_{\mathrm{s}}$ that depends on specific growth rate (see Fig. 4). An exception was made for the WT $K_{\mathrm{s}}$ of cells growing at $0 \cdot 1 \mathrm{~h}^{-1}$. This $K_{\mathrm{s}}$ value was not fixed at the value indicated in Fig. 4 but was allowed to roam freely during parameter estimation (see below). (iii) Mutant phenotypes (i.e. phenotype 1 ) with an improved $\mu_{\max }$ and $K_{\mathrm{s}}$ are produced from the WT with a certain mutation rate. The mutation rate is defined as the number of advantageous mutations per cell per generation. The $\mu_{\max }$ of phenotype 1 was as determined experimentally $\left(0.67 \mathrm{~h}^{-1}, 0.73 \mathrm{~h}^{-1}\right.$ or $0.78 \mathrm{~h}^{-1}$ for populations cultivated at $0.1 \mathrm{~h}^{-1}, 0.3 \mathrm{~h}^{-1}$ or $0.53 \mathrm{~h}^{-1}$, respectively), whereas the improvement of $K_{\mathrm{s}}$ was estimated by AQUASIM. This leads to an out-competition of the WT by the phenotype 1. (iv) When phenotype 1 has reached a certain population size ( $>1 /$ mutation rate), phenotype 2 with a lower $K_{\mathrm{s}}$ is generated from phenotype 1 at each replication, whereas $\mu_{\max }$ now stays constant. Phenotype 2 will out-compete phenotype 1 because of its improved $K_{\mathrm{s}}$. (v) Phenotypes 3, 4 and 5 are generated from phenotype 2, 3 and 4, respectively, in the same way. It should be noted that we use the term phenotype here not for a cell line carrying a defined mutation but for a group of different mutants that have the same improved kinetic properties with respect to $\mu_{\max }$ and $K_{\mathrm{s}}$ on glucose [compare with Notley-McRobb \& Ferenci $(2000,1999 \mathrm{a}, \mathrm{b})]$. This process is illustrated in Fig. 5.

\begin{tabular}{|c|c|c|c|c|c|c|c|c|}
\hline WT & $\longrightarrow$ & phenotype 1 & $\rightarrow$ & phenotype 2 & $\longrightarrow$ & phenotype 3 & $\longrightarrow$ & phenotype 4 \\
\hline$K_{\mathrm{s}(\mathrm{WT})}$ & $>$ & $K_{\mathrm{s}(\text { phenotype } 1)}$ & $>$ & $K_{\mathrm{s}(\text { phenotype 2) }}$ & $>$ & $K_{\mathrm{s}(\text { phenotype } 3)}$ & $>$ & $K_{\mathrm{s}(\text { phenotype } 4)}$ \\
\hline$\mu_{\max (\mathrm{WT})}$ & $<$ & $\mu_{\max (\text { phenotype 1) }}$ & $=$ & $\mu_{\max (\text { phenotype 2) }}$ & $=$ & $\mu_{\max (\text { phenotype 3) }}$ & $=$ & $\mu_{\max (\text { phenotype 4) }}$ \\
\hline
\end{tabular}

Fig. 5. Schematic illustration of the succession of mutated phenotypes and their relationship with respect to kinetic parameters. Note that each phenotype can represent a mixture of different mutants with the same phenotype with respect to $K_{\mathrm{s}}$ and $\mu_{\max }$. 
Table 3. Correlation coefficients of the fitted parameters (see also Table 2) as estimated by AQUASIM

At values lower than 0.95 parameters are considered to be identifiable.

\begin{tabular}{|c|c|c|c|c|c|c|}
\hline & \multicolumn{6}{|c|}{$0 \cdot 1 \mathrm{~h}^{-1}$} \\
\hline & $K_{\mathrm{s}, \mathrm{WT}}$ & $K_{\mathrm{s}, 1}$ & $K_{\mathrm{s}, 2}$ & $K_{\mathrm{s}, 3}$ & $K_{\mathrm{s}, 4}$ & $m r$ \\
\hline$K_{\mathrm{s}, \mathrm{wT}}$ & $1 \cdot 00$ & 0.63 & -0.03 & $-0 \cdot 16$ & $-0 \cdot 24$ & -0.45 \\
\hline$K_{\mathrm{s}, 1}$ & 0.63 & $1 \cdot 00$ & 0.66 & 0.55 & $0 \cdot 46$ & $0 \cdot 14$ \\
\hline$K_{\mathrm{s}, 2}$ & -0.03 & 0.66 & $1 \cdot 00$ & $0 \cdot 94$ & $0 \cdot 87$ & 0.79 \\
\hline$K_{\mathrm{s}, 3}^{\mathrm{s}, 2}$ & $-0 \cdot 16$ & 0.55 & $0 \cdot 94$ & $1 \cdot 00$ & $0 \cdot 91$ & $0 \cdot 85$ \\
\hline$K_{\mathrm{s}, 4}$ & $-0 \cdot 24$ & 0.46 & $0 \cdot 87$ & $0 \cdot 91$ & $1 \cdot 00$ & $0 \cdot 83$ \\
\hline \multirow[t]{3}{*}{$m r$} & $-0 \cdot 45$ & $0 \cdot 14$ & 0.79 & $0 \cdot 85$ & $0 \cdot 83$ & 1.00 \\
\hline & \multicolumn{6}{|c|}{$0 \cdot 3 \mathrm{~h}^{-1}$} \\
\hline & $K_{\mathrm{s}, 1}$ & $\boldsymbol{K}_{\mathrm{s}, 2}$ & $K_{\mathrm{s}, 3}$ & $K_{\mathrm{s}, 4}$ & $m r$ & \\
\hline$K_{\mathrm{s}, 1}$ & $1 \cdot 00$ & 0.47 & $0 \cdot 32$ & $0 \cdot 35$ & $0 \cdot 38$ & \\
\hline$K_{\mathrm{s}, 2}^{\mathrm{s}, 1}$ & $0 \cdot 47$ & $1 \cdot 00$ & $0 \cdot 77$ & 0.69 & $0 \cdot 72$ & \\
\hline$K_{\mathrm{s}, 3}$ & $0 \cdot 32$ & 0.77 & $1 \cdot 00$ & $0 \cdot 70$ & $0 \cdot 74$ & \\
\hline$K_{\mathrm{s}, 4}$ & $0 \cdot 35$ & 0.69 & $0 \cdot 70$ & $1 \cdot 00$ & $0 \cdot 87$ & \\
\hline \multirow[t]{3}{*}{$m r$} & $0 \cdot 38$ & 0.72 & $0 \cdot 74$ & $0 \cdot 87$ & $1 \cdot 00$ & \\
\hline & \multicolumn{6}{|c|}{$0.53 \mathrm{~h}^{-1}$} \\
\hline & $K_{\mathrm{s}, 1}$ & $\boldsymbol{K}_{\mathrm{s}, 2}$ & $K_{\mathrm{s}, 3}$ & $K_{\mathrm{s}, 4}$ & $K_{\mathrm{s}, 5}$ & $m r$ \\
\hline$K_{\mathrm{s}, 1}$ & $1 \cdot 00$ & 0.57 & $0 \cdot 31$ & $0 \cdot 21$ & $0 \cdot 13$ & -0.09 \\
\hline$K_{\mathrm{s}, 2}^{\mathrm{s}, 1}$ & 0.57 & $1 \cdot 00$ & 0.54 & $0 \cdot 39$ & $0 \cdot 36$ & $0 \cdot 30$ \\
\hline$K_{\mathrm{s}, 3}$ & $0 \cdot 31$ & 0.54 & $1 \cdot 00$ & $0 \cdot 78$ & $0 \cdot 63$ & $0 \cdot 68$ \\
\hline$K_{\mathrm{s}, 4}^{\mathrm{s,0}}$ & $0 \cdot 21$ & $0 \cdot 39$ & 0.78 & $1 \cdot 00$ & $0 \cdot 67$ & $0 \cdot 70$ \\
\hline$K_{\mathrm{s}, 5}$ & $0 \cdot 13$ & $0 \cdot 36$ & 0.63 & 0.67 & $1 \cdot 00$ & $0 \cdot 71$ \\
\hline$m r$ & -0.09 & $0 \cdot 30$ & $0 \cdot 68$ & $0 \cdot 70$ & $0 \cdot 71$ & 1.00 \\
\hline
\end{tabular}

AQUASIM estimated mutation rates and improved $K_{\mathrm{S}}$ values of each phenotype by fitting measured residual glucose concentrations to calculated ones (see Methods). The $K_{\mathrm{s}}$ values and mutation rates for the best fits for each dilution rate are given in Table 2. Table 3 shows the correlation coefficients of the estimated parameters. Estimated $K_{\mathrm{s}}$ values and mutation rates were used to predict the evolution of the residual concentration (lines in Fig. 1) and the population dynamics of postulated mutant phenotypes (Fig. 6). The population dynamics show that some of the phenotypes dominate the culture longer than others (Fig. 6). This is reflected in the course of the residual glucose concentration where sometimes plateaux can be recognized between the changeovers from one population to the next. Mostly, such plateaux are very short-lived and smoothed by rapid successive population changeovers.

As stated above, the WT $K_{\mathrm{s}}$ at $0 \cdot 1 \mathrm{~h}^{-1}$ was not determined as in Fig. 4, but estimated by AQUASIM. Because physiological adaptation of cells to chemostat conditions takes 5-10 volume changes, values determined in the first $20 \mathrm{~h}$ as those in Fig. 4 are probably too high, because cells are not yet fully adapted. On the other hand, values determined after 5-10 volume changes $\left(50-100 \mathrm{~h}\right.$ at $\left.D=0 \cdot 1 \mathrm{~h}^{-1}\right)$ are probably too low because after this time period mutants with improved $K_{\mathrm{s}}$ are very likely to account for a good part of the culture.

\section{Evolution of $\boldsymbol{K}_{\mathrm{s}}$ at low cell numbers}

There are $10^{11}$ individuals in the large chemostats and the estimated mutation rate (advantageous mutations per cell per generation) lies at about $10^{-7}$. The product of the population size (number of cells) times the mutation rate gives the mean number of cells with advantageous mutations that are produced in the whole population within one generation interval. Since this product is much higher than one $\left(10^{11} \times 10^{-7}=10^{4}\right)$ in large chemostats the system does not have to wait for a favourable mutation to occur, but only for the existing favourable mutations to sweep the population (Wahl \& Krakauer, 2000). This is the reason for the high reproducibility and deterministic behaviour of the evolutionary process observed (Fig. 1). If the population size is around $10^{7}$ cells, the mean number of cells with 


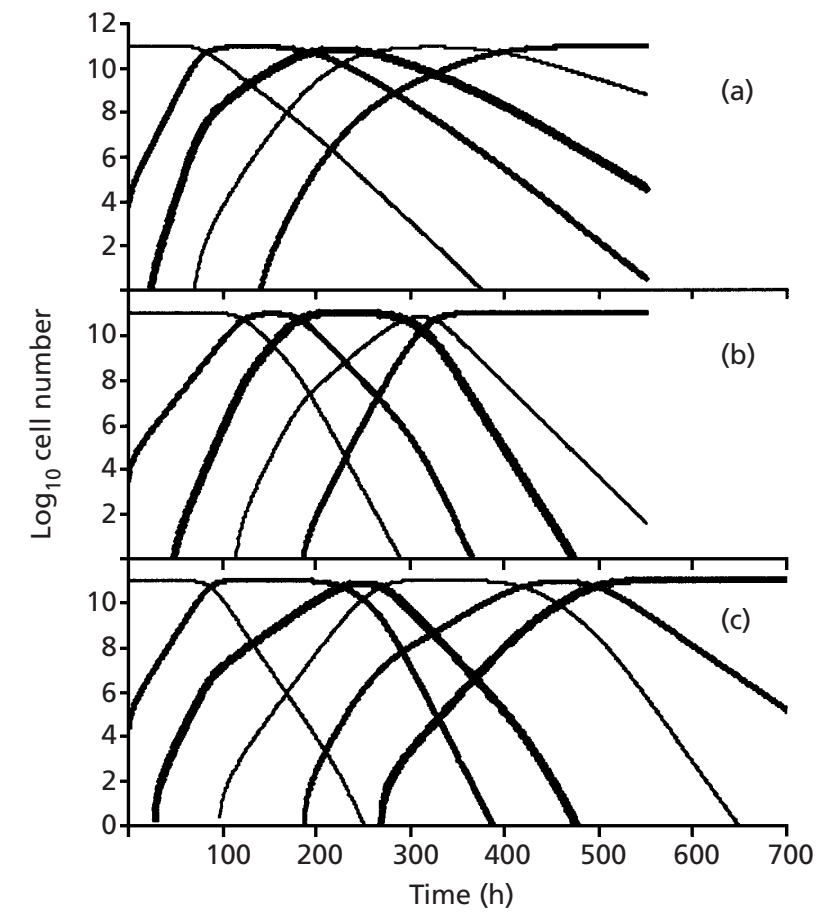

Fig. 6. Succession of wild-type and phenotypes with improved kinetic properties (compare with Fig. 5) in glucose-limited chemostats of $E$. coli $\mathrm{K}-12$ run at dilution rates of $0.1 \mathrm{~h}^{-1}(\mathrm{a})$, $0.3 \mathrm{~h}^{-1}$ (b) and $0.53 \mathrm{~h}^{-1}$ (c) as predicted using AQUASIM with the kinetic parameters shown in Table 2.

advantageous mutations arising at each generation interval is only one. This means that there is a high probability of no advantageous mutations taking place during a generation interval in the whole population. Hence, the evolution in populations with a total cell count in the range of $1 /$ (mutation rate) should start to become stochastic and lose its reproducibility. Therefore, we followed the evolution of the residual glucose concentration in four much smaller populations, consisting of total cell numbers between $1 \times 10^{7}$ and $5 \times 10^{7}$. To achieve this, we decreased both the glucose concentration (from $100 \mathrm{mg} \mathrm{l}^{-1}$ to $1 \mathrm{mg} \mathrm{l}^{-1}$ ) and the reactor size (from $1500 \mathrm{ml}$ to $75 \mathrm{ml}$ ). As predicted, the time course of the residual glucose concentration was different for all four populations (Fig. 7). Besides the lack of reproducibility between different runs, the evolution of the residual glucose concentration was slower in all four small bioreactors compared to the large bioreactors. The residual glucose concentration started to decrease later in three of the four small bioreactors. Only in one population, which was cultivated for $750 \mathrm{~h}$, the residual glucose concentration decreased to about $50 \mu \mathrm{g} \mathrm{l^{-1 }}$ after 600-700 h. Populations in large bioreactors typically reached this residual glucose concentration after 400-500 h. Moreover, plateaux, which can only be estimated in the large bioreactors, are much more pronounced in the small bioreactors. These plateaux indicate $K_{\mathrm{s}}$ values of mutants. For small populations one would expect to observe quite extended plateaux in the
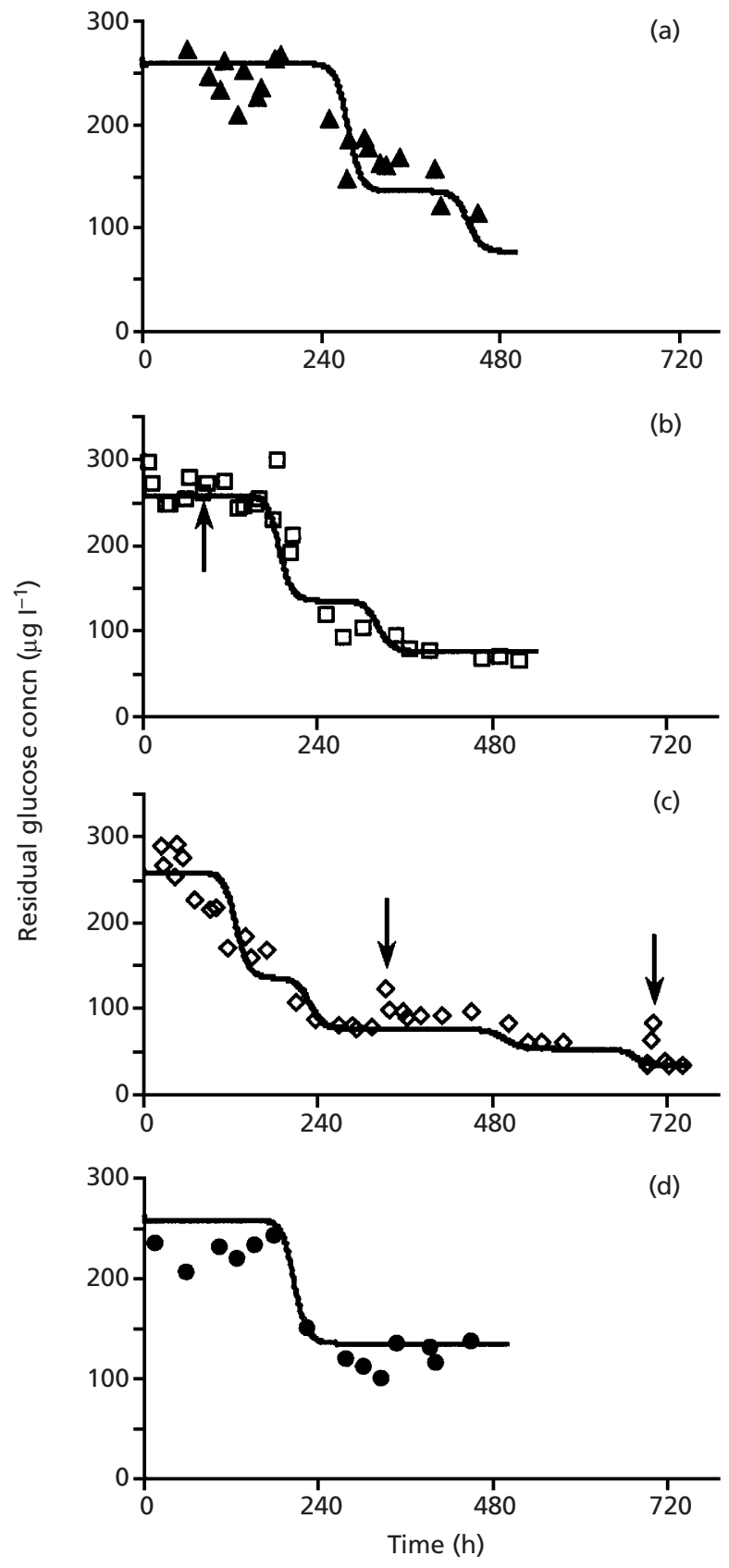

Fig. 7. Evolution of the residual glucose concentrations of four independent glucose-limited chemostats of $E$. coli K-12 run at a dilution rate of $0.3 \mathrm{~h}^{-1}$ and containing a total population of $1-5 \times 10^{7}$ cells. Experimental data (symbols) and model predictions (lines) are shown. At the time points indicated by arrows, the cultures were transferred to a fresh bioreactor vessel. Model predictions were performed with the parameters from Table 2. In contrast to the procedure followed in Fig. 1, the mutated phenotypes (for kinetic properties see Fig. 5 and Table 2) were not produced with a given frequency from the growing population, but were introduced into the population at arbitrarily chosen time points. One cell with a mutated phenotype was introduced into a population of $10^{7}$ cells at the following time points. (a) Phenotype 1 at $150 \mathrm{~h}$, phenotype 2 at $300 \mathrm{~h}$. (b) Phenotype 1 at $60 \mathrm{~h}$, phenotype 2 at $190 \mathrm{~h}$. (c) Phenotype 1 at $0 \mathrm{~h}$, phenotype 2 at $110 \mathrm{~h}$, phenotype 3 at $300 \mathrm{~h}$, phenotype 4 at $530 \mathrm{~h}$. (d) Phenotype 1 at $80 \mathrm{~h}$. 


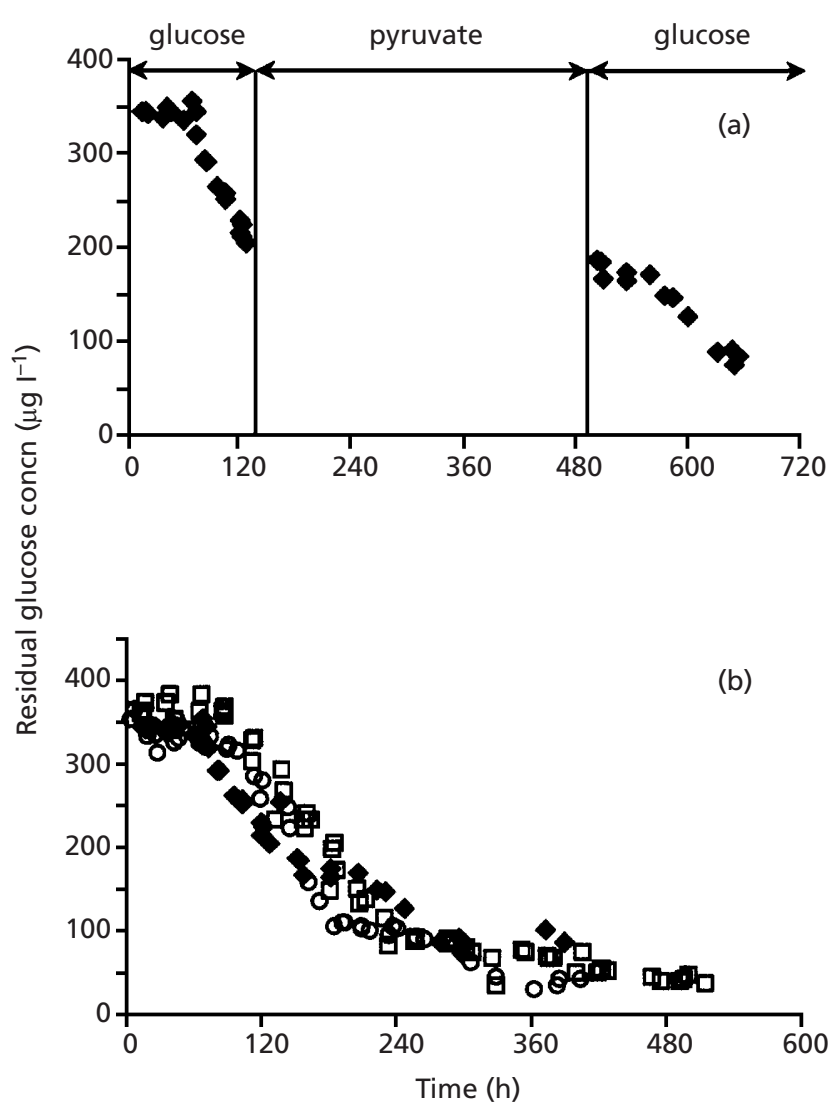

Fig. 8. Evolution of the residual glucose concentration in a continuous culture of $E$. coli K-12. The culture was operated at $D=0.3 \mathrm{~h}^{-1}$ under glucose-limited conditions for $128 \mathrm{~h}$, then switched to pyruvate-limited conditions at $0.1 \mathrm{~h}^{-1}$ for $353 \mathrm{~h}$ and subsequently switched back to glucose-limited conditions at $0.3 \mathrm{~h}^{-1}$. Uncorrected data (a) and data corrected for growth on glucose only (b) are shown ( $\downarrow)$. Data from continuous cultivations grown under glucose limitation at $D=0.3 \mathrm{~h}^{-1}$ without interruption are shown for comparison in (b) $(\bigcirc, \square)$.

case where a population has to wait for the next mutation to occur and to take over. Therefore, we performed computer simulations of evolutionary processes, where mutants were not produced as a certain fraction of the growing population but introduced into the system at arbitrarily chosen time points. The expected residual glucose concentrations for such evolving cultures are shown as lines in Fig. 7 . In fact, the predicted plateaux are in good agreement with the experimentally observed extended plateaux, thus supporting the estimated $K_{\mathrm{s}}$ values of the four mutants listed in Table 2.

Interestingly the analytically determined residual glucose concentrations in the small chemostats were only about $75 \%$ of those measured in the large bioreactors. Therefore, the lines plotted in Fig. 7 are adjusted by this factor. The reason for this reproducible deviation is not known, but wall populations might account for this difference. Wall populations decrease the residual glucose concentration in reactors and would have a larger effect in the small chemostats, because of the higher surface to volume ratio and lower cell density compared to the large chemostats. Such a wall population would have to build up quickly and reproducibly since initial steady state values in the four independent chemostats were similar and established rapidly. Moreover, when we transferred whole cultures to a fresh bioreactor after different cultivation times (indicated by arrows in Fig. 7), the residual glucose concentration increased just after the transfer. Within a few hours after the transfer, the steady state was reached again and the residual glucose concentration was the same as before the transfer. Thus, it is possible that a wall population led to generally lower glucose levels in the small chemostats, but it seems unlikely that the wall population has a considerable effect on the long-term evolution of the residual glucose concentration, on which this study focused.

\section{Evolution of $\kappa_{\mathrm{s}}$ after a shift to pyruvate}

To test how the $K_{\mathrm{s}}$ for glucose of a population evolves when the selection pressure to increase glucose affinity is relieved, a culture grown under glucose limitation for $128 \mathrm{~h}$ at $D=0.3 \mathrm{~h}^{-1}$ (57 generations) was shifted to pyruvate limitation. The culture was then grown under pyruvate limitation at $D=0 \cdot 1 \mathrm{~h}^{-1}$. ( $D$ was reduced because $\mu_{\max }$ for growth with pyruvate was only

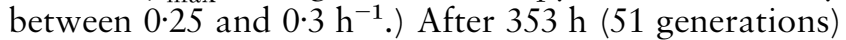
the culture was shifted back to glucose limitation and $D=0 \cdot 3 \mathrm{~h}^{-1}$ (Fig. 8a). Astonishingly, the residual concentration of glucose immediately established again at the value measured before the shift to pyruvate and continued to decrease (Fig. 8a). Hence, the temporal shift from glucose to pyruvate limitation did not affect the evolution of the affinity for glucose, because after the shift back to glucose limitation the residual glucose concentration followed a time-course starting at the exact value before the interruption and exactly paralleling the pattern of cultures that were not submitted to the temporal shift (Fig. 8b). This demonstrates that the selective evolution during growth of an E. coli population with glucose can be followed easily in a continuous culture by monitoring the residual concentration of this sugar.

\section{DISCUSSION}

\section{Effects of Monod kinetics on population dynamics}

This study has provided experimental data for an evolutionary process, which can be described with a deterministic model in large populations and which becomes stochastic when the population size is in the range of $1 /$ (mutation rate) or smaller. Moreover, it has been demonstrated how a selection-driven evolution, like the one studied here and investigated previously (Dykhuizen \& Hartl, 1981; Hartl \& Dykhuizen, 1979), can proceed as a function of absolute time passed (i.e., clock-like) rather than as a function of the number of generations. We want to emphasize that the model presented here can explain the apparent clock-like behaviour for this special case of selection-driven 


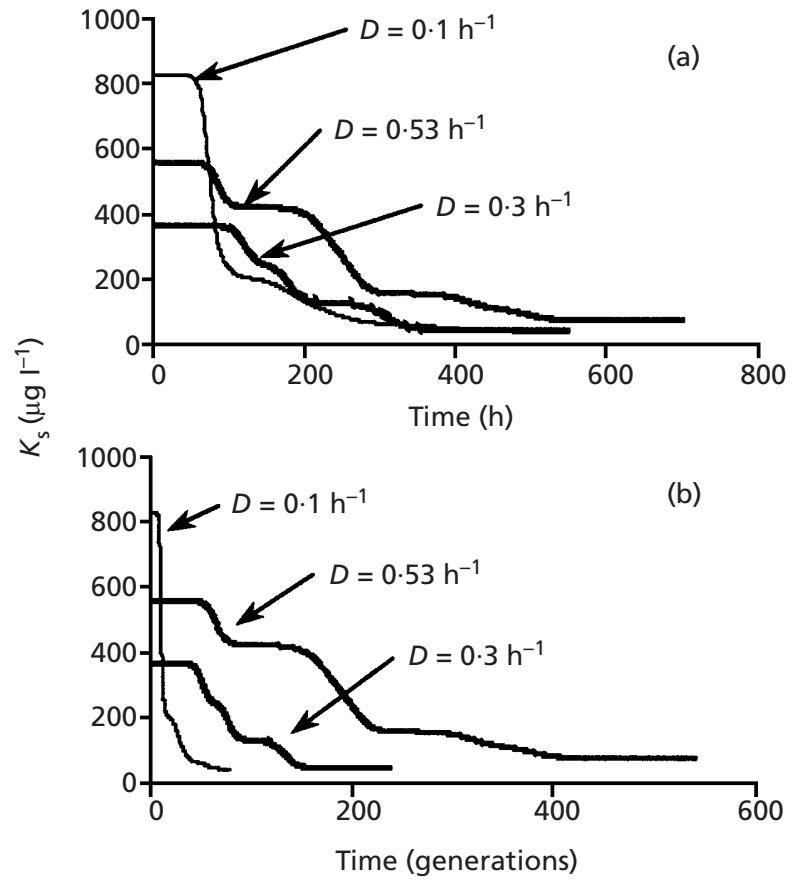

Fig. 9. Evolution of $K_{\mathrm{s}}$ in glucose-limited chemostats of $E$. coli $\mathrm{K}-12$ run at dilution rates of $0.1 \mathrm{~h}^{-1}, 0.3 \mathrm{~h}^{-1}$ and $0.53 \mathrm{~h}^{-1}$. The evolution is given either as a function of time measured in hours (a), or of generations (b). The comparison demonstrates that the glucose evolution pattern is more related to absolute elapsed time than to the number of generations.

chemostat evolution under glucose limitation, but of course, it does not serve as a general explanation for the molecular clock observed in amino acid substitution rates (Zuckerkandl \& Pauling, 1965). The apparent clock-like behaviour becomes evident when we plot the time-course of the improvement of $K_{\mathrm{s}}$ either as a function of time (Fig. 9a) or as a function of generations (Fig. 9b). At dilution rates of $0 \cdot 3 \mathrm{~h}^{-1}$ and $0 \cdot 1 \mathrm{~h}^{-1}$ the evolution of $K_{\mathrm{s}}$ is almost identical and, except for the first $100 \mathrm{~h}$, the $K_{\mathrm{s}}$ exhibited by the evolving cultures is always similar. The evolution at $0.53 \mathrm{~h}^{-1}$ is also quite similar, although $K_{\mathrm{s}}$ values are always higher at given time points.

The model used here predicted similar improvements for $K_{\mathrm{s}}$ for most of the mutations $\left(F_{\mathrm{i}} \cong 0 \cdot 6\right.$, Table 2$)$. Therefore, first we will discuss how fast a population is expected to evolve at different growth rates, when $K_{\mathrm{s}}$ improvements are the same. Later we will discuss the influence of the first mutational step (from WT to phenotype 1), where the improvements in kinetic properties were different at the various growth rates.

For two competing strains with the same $\mu_{\max }$ but different $K_{\mathrm{s}}\left(K_{\mathrm{s}, 1}>K_{\mathrm{s}, 2}\right)$, the selection coefficient per hour $\left(S_{\mathrm{h}}\right)$, i.e. the specific growth rate difference between the two strains growing together in the same chemostat, can be calculated as follows:

$S_{\mathrm{h}}=\mu_{\max } \frac{s}{K_{\mathrm{s}, 1}+s}-\mu_{\max } \frac{s}{K_{\mathrm{s}, 2}+s}$

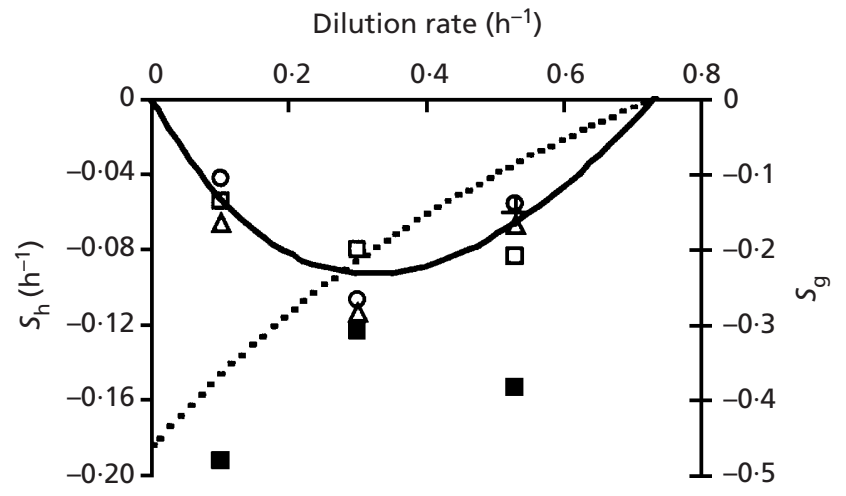

Fig. 10. Model prediction of the two selection coefficients, selection per hour, $S_{\mathrm{h}}$ (solid line), and selection per generation, $S_{g}$ (dotted line), for two competing strains with the following kinetic properties: $\mu_{\max , 1}=\mu_{\max , 2}=0.73 \mathrm{~h}^{-1}$ and $K_{\mathrm{s}, 2} / K_{\mathrm{s}, 1}=0.6$. Selection coefficients per hour are specific growth rate differences between the two strains when grown together at the given dilution rate under the assumption that the residual glucose concentration is as if only the strain with the higher $K_{\mathrm{s}}$ were present in the chemostat. Note that more negative values mean higher selection and hence faster evolution. The selection coefficients per hour for strains with $K_{\mathrm{s}}$ and $\mu_{\max }$ values calculated for our experimental data are also given: phenotype 1 against WT ( $\square)$, phenotype 2 against phenotype $1(\triangle)$, phenotype 3 against phenotype $2(\square)$, phenotype 4 against phenotype $3(\bigcirc)$ and phenotype 5 against phenotype $4(+)$. Note that the $S_{h}$ values for the competition of phenotype 1 against WT at $0.1 \mathrm{~h}^{-1}$ and $0.53 \mathrm{~h}^{-1}$ differed markedly from the other $S_{h}$ values.

and the selection coefficient per generation $\left(S_{\mathrm{g}}\right)$ is calculated as :

$S_{\mathrm{g}}=\frac{(\ln 2) S_{\mathrm{h}}}{D}$

(Dykhuizen \& Hartl, 1983), where $s$ is the residual glucose concentration in the chemostat. In the term $s /\left(K_{\mathrm{s}}+s\right)$, the same proportional change in $K_{\mathrm{s}}$ has a greater impact on the selection pressure at lower than at higher $s$ values. Substrate concentrations in the chemostat become lower with decreasing dilution rates. This is the reason why $S_{\mathrm{g}}$ steadily decreases with decreasing dilution rates (Fig. 10). However, when we calculate the selection coefficient per hour, $S_{\mathrm{h}}$, there are two effects counterbalancing each other. On the one hand, there is the selection pressure per generation, $S_{\mathrm{g}}$, which speeds up the evolution of slower growing populations compared to faster growing populations. But on the other hand, there are more generations per time interval at higher dilution rates, speeding up the evolution of faster growing populations compared to slower growing populations. The combination of these effects leads to a maximum rate of evolution at intermediary growth rates. This is visualized in the selection coefficient per hour, $S_{\mathrm{h}}$, which shows a u-shaped curve (Fig. 10). Note that more negative values mean higher selection and hence faster evolution.

In the following we want to calculate this maximum rate of evolution as a function of the different $K_{\mathrm{s}}$ values of the 
competing strains. Since the residual glucose concentration is constantly changing during a competition experiment, we first need to know what concentrations we have to base our calculations on. Normally competitions are started with equal numbers of the competing strains. In this case the residual glucose concentration in the chemostat is as though only the better of the two strains (with the lower $K_{\mathrm{s}}$ ) was in the chemostat (Dykhuizen \& Hartl, 1983). In contrast, when evolution of successive mutants is considered, mutants are generated as a strong minority $\left(10^{-7} \times\right.$ the total cell count $)$ in an environment where $s$ is given by the parent strain (with the higher $K_{\mathrm{s}}$ ). When the population size is much higher than $1 /$ (mutation rate), consecutive mutants are generated already before the precedent mutant has completely taken over the population. Therefore, the evolutionrelevant selection coefficients have to be calculated based on $s$ values as if only the strain with the higher $K_{\mathrm{s}}$ was in the chemostat:

$s=D \frac{K_{\mathrm{s}, 1}}{\mu_{\max }-D}$

Hence $S_{\mathrm{h}}$ can be calculated as:

$S_{\mathrm{h}}=D-\mu_{\max } \frac{K_{\mathrm{s}, 1} D}{K_{\mathrm{s}, 2} \mu_{\max }+\left(K_{\mathrm{s}, 1}-K_{\mathrm{s}, 2}\right) D}$

The minimum of this function is found when the first derivative is set to 0 and it is positioned at

$D_{\min }=\mu_{\max } \frac{\left(K_{\mathrm{s}, 1} K_{\mathrm{s}, 2}\right)^{\frac{1}{2}}-K_{\mathrm{s}, 2}}{K_{\mathrm{s}, 1}-K_{\mathrm{s}, 2}}$

which can also be written independently of absolute values of $K_{\mathrm{s}, 1}$ and $K_{\mathrm{s}, 2}$ as

$D_{\min }=\mu_{\max } \frac{\left(F_{\mathrm{i}}\right)^{\frac{1}{2}}-F_{\mathrm{i}}}{1-F_{\mathrm{i}}}$

where $F_{\mathrm{i}}=K_{\mathrm{s}, 2} / K_{\mathrm{s}, 1}$ and is referred to as the improvement factor. Therefore, a system in which the proportional improvement in $K_{\mathrm{s}}$ is the same at all dilution rates will evolve at the fastest pace (i.e. the most rapid mutant successions) at a dilution rate of $D_{\min }$. For values of $F_{\mathrm{i}}$ between 0.9 and $0 \cdot 1, D_{\min }$ lies between $0.49 \times \mu_{\max }$ and $0.24 \times \mu_{\max }$. Note that $D_{\min }$ is always lower than $0.5 \times \mu_{\max }$, since 0.5 is the boundary value of the term $\left(F_{\mathrm{i}}\right)^{\frac{1}{2}} /\left(1-F_{\mathrm{i}}\right)$ when $F_{\mathrm{i}}$ approaches 1 .

For the mean improvement in $K_{\mathrm{s}}$ found in this study, i.e. $F_{\mathrm{i}}=0 \cdot 6$, and $\mu_{\max }$ values that increase from $0 \cdot 67 \mathrm{~h}^{-1}$ to $0.78 \mathrm{~h}^{-1}$ between the dilution rates of $0.1 \mathrm{~h}^{-1}$ and $0.53 \mathrm{~h}^{-1}$, the fastest evolution should be observed at about $0 \cdot 32 \mathrm{~h}^{-1}$. However, the first mutational step predicted by the model (from WT to phenotype 1) is special, because not only $K_{\mathrm{s}}$ but also $\mu_{\max }$ improved. Moreover, the improvements for $K_{\mathrm{s}}$ and $\mu_{\max }$ were very different between dilution rates. The effects of these differences on the overall rate of the observed evolution will be discussed next.

In the system studied here, the dependence of the initial
WT $K_{\mathrm{s}}$ on the dilution rate (Fig. 4) also exhibits a ushaped pattern similar to that of the $S_{\mathrm{h}}$ values (Fig. 10). As a result and as estimated by AQUASIM (Table 2), the improvement in $K_{\mathrm{s}}$ in the first 100-200 h of cultivation is much higher at $0.1 \mathrm{~h}^{-1}$ than at $0.3 \mathrm{~h}^{-1}$, accelerating the evolution at $0 \cdot 1 \mathrm{~h}^{-1}$ compared to $0 \cdot 3 \mathrm{~h}^{-1}$ and thus cancelling the effect of the higher selection per hour at $0 \cdot 3 \mathrm{~h}^{-1}$ in the initial phase. Later when the improvement in $K_{\mathrm{s}}$ is in a similar proportional range for $0 \cdot 1 \mathrm{~h}^{-1}$ and $0.3 \mathrm{~h}^{-1}$, predicted population changeovers will become faster at the dilution rate of $0 \cdot 3 \mathrm{~h}^{-1}$ (Fig. 6). In comparison to the culture run at $0 \cdot 3 \mathrm{~h}^{-1}$, the predicted mutant phenotype 1 takes over faster at the beginning of the selection process in the chemostats run at $0 \cdot 1 \mathrm{~h}^{-1}$ and at $0.53 \mathrm{~h}^{-1}$, respectively. However, despite the same outcome, the phenomenon is based on different kinetic reasons. In the $0 \cdot 1 \mathrm{~h}^{-1}$ chemostat it is mainly the improvement in $K_{\mathrm{s}}$ which makes phenotype 1 better than in $0.3 \mathrm{~h}^{-1}$ chemostats, whereas in $0.53 \mathrm{~h}^{-1}$ chemostats it is mainly the improvement in $\mu_{\max }$ that makes phenotype 1 of the $0.53 \mathrm{~h}^{-1}$ chemostat better (compare parameter values in Table 2).

Based on the above considerations, we can conclude that there is an apparent overall clock-like behaviour due to the special combination of Monod kinetics (Fig. 10) and the different initial $K_{\mathrm{s}}$ and $\mu_{\max }$ improvements. When we only look at the sweeps where $K_{\mathrm{s}}$ improvements are the same for the different dilution rates, a maximum rate of evolution slightly below $\mu_{\max } / 2$ is observed. With higher and lower growth rates the evolution slows down and a certain rate of evolution occurs exactly twice (Fig. 10, solid line). Therefore, it is possible that populations with highly different generation times (i.e. at very high and very low growth rates) evolve at the same speed, but no constant speed of evolution is expected over the whole range of dilution rates.

The model has shown that such an apparent clock-like evolution can be explained with very similar mutation rates per generation and similar improvements in $K_{\mathrm{s}}$ per mutation at different growth rates. It is therefore not mandatory to assume different mutation rates to explain a phenomenon such as that shown in Fig. 9. However, mutation rates can depend on many experimental factors, and growth rate may be one of them (Smith, 1992). For E. coli populations growing under glucoselimited conditions there is contradictory information about the dependence of mutation rate on specific growth rate. Whereas studies on mutations to bacteriophage T5 resistance could not find such a dependence (Kubitschek \& Bendigkeit, 1964), Savva (1982) reported that mutations from tryptophan auxotrophy to prototrophy increased proportionally with specific growth rate. Note that one has to be careful when comparing mutation rates from different studies. Throughout this report we give mutation rates as the number of advantageous mutations per cell per generation [as in Savva (1982)], whereas in the literature mutation rate is sometimes also defined as the number of mutations per bacterium per hour (Kubitschek \& Bendigkeit, 1964). 
The mutation rates calculated here are in the same range as those reported commonly in the literature, which vary typically between $10^{-6}$ and $10^{-9}$ mutations per cell and generation for a range of different detectable phenotypes (Merrel, 1981). Notley-McRobb \& Ferenci (2000) estimated that in their glucose-limited chemostats $(D=$ $0 \cdot 3 \mathrm{~h}^{-1}$ ), containing $2-3 \times 10^{10}$ cells in total, $10^{4}$ mutants with an improved glucose affinity were generated at each replication round due to loss-of-function mutations in $m g l$ and $m l c$. This suggests a mutation rate of $3-5 \times 10^{-7}$, which is very similar to the mutation rates estimated in this study, namely $1-5 \times 10^{-7}$ at all dilution rates tested.

Our results are in good agreement with the studies of Dykhuizen and Hartl (Dykhuizen \& Hartl, 1981; Hartl \& Dykhuizen, 1979). We also observed an increase in $\mu_{\max }$ during the first $50-150 \mathrm{~h}$. After this phase, $\mu_{\max }$ became stable in both studies for the following $400 \mathrm{~h}$, whereas $K_{\mathrm{s}}$ improved constantly. Also the apparent clock-like improvement in $K_{\mathrm{s}}$ was observed here (Fig. 9). The two studies differed with respect to the observed increase in $\mu_{\max }$ and the extent of $K_{\mathrm{s}}$ improvement during the 500 h. Whereas Dykhuizen \& Hartl (1981) found that the decrease of $K_{\mathrm{S}}$ was tapering off in later periods; we observed that the stepwise improvements in $K_{\mathrm{s}}$ were quite constant. Furthermore, these authors reported similar improvements in $\mu_{\max }$ at both dilution rates, we observed that the improvement in $\mu_{\max }$ was greater at higher dilution rates. A selection for increasing $\mu_{\max }$ with increasing growth rates can be explained with the concept of $\mu_{\max ^{-}}$and $K_{\mathrm{s}}$-type strategists, which postulates that batch cultures select for quickly growing ( $\mu_{\max }$-type) organisms, whereas in a chemostat at low dilution rates, slow-growing cells with a high affinity for the limiting substrate $\left(K_{\mathrm{s}}\right.$-type) are selected for (Powell, 1958; Veldkamp \& Jannasch, 1972). In fact, in the chemostat the growth rate can be varied from very slow growth to rates close to $\mu_{\max }$; thus it allows mimicking of a transition state between ' $\mu_{\max }$-type-only' and ' $K_{\mathrm{s}}$ type-only' selection. The values reported here for the improvement in $\mu_{\max }$ and $K_{\mathrm{s}}$ demonstrated such a transition: with increasing specific growth rate the improvement of $\mu_{\max }$ became bigger, whereas the improvement in $K_{\mathrm{s}}$ was smaller (Table 2). The genetic events leading to this improvement in $\mu_{\max }$ are not yet understood.

\section{Growth rate dependence of $\boldsymbol{K}_{\mathrm{s}}$}

In contrast to one of the assumptions of the Monod model and to measurements performed with evolved strains (Kováŕová et al., 1996; Senn et al., 1994), starting clones of the WT strain used here exhibited a dependence of $K_{\mathrm{s}}$ on dilution rate. At dilution rates lower than $0.3 \mathrm{~h}^{-1}$, this dependence is mainly due to rpoS as demonstrated by the comparison of the WT and the otherwise isogenic rpoS mutant (Fig. 4). The negative effect on $K_{\mathrm{s}}$ and, hence, on the competitive ability of a strain with high RpoS levels might be one reason why many isolates from carbon-limited environments such as starved batch cultures or environmental habitats show an attenuated RpoS phenotype (Finkel et al.,
1998; Zambrano et al., 1993). The dependence of $K_{\mathrm{s}}$ on dilution rate determined here from residual glucose concentrations is in good agreement with earlier studies by Ferenci and co-workers, who demonstrated that the expression of the high-affinity glucose-uptake pathway is maximal at intermediate growth rates, getting lower towards both higher and lower growth rates (summarized by Ferenci, 1996, 1999). The lower glucose affinity at enhanced dilution rates results from reduced cAMP and endoinducer levels, which are necessary for the induction of the high affinity glucose transport systems (Death \& Ferenci, 1994; Ferenci, 1996).

\section{Limitations in monitoring evolution}

Monitoring evolution by measuring residual substrate concentrations has its limits because the growth-limiting substrate(s) must be known. In this study this growthlimiting substrate was glucose. However, as the evolution proceeds, not all cells of the population may show the same values of these parameters.

For example, Adams and co-workers have found that $E$. coli populations cultivated under glucose-limited conditions evolve polymorphisms maintained by acetate crossfeeding (Rosenzweig et al., 1994). Such polymorphisms were found only in populations cultivated for $1615 \mathrm{~h}$ (at $D=0 \cdot 2 \mathrm{~h}^{-1}$, corresponding to 468 generations) or more (Treves et al., 1998).

However, in the first 500-700 h, evolution of such E. coli populations triggers the improvement of growth kinetics on glucose. Notley-McRobb and Ferenci have analysed mutations occurring in populations during the first $644 \mathrm{~h}$ of cultivation $\left(280\right.$ generations at $\left.D=0 \cdot 3 \mathrm{~h}^{-1}\right)$. All of 10-20 randomly picked isolates had acquired mutations in the $m l c, m g l$ and mal loci, all of which confer an increased competitive ability in glucose scavenging (Notley-McRobb \& Ferenci, 1999a, b). In a later study the appearance of these $m l c$ and $m g l$ mutations was directly correlated to periodic population shifts (NotleyMcRobb \& Ferenci, 2000).

Proteomic analysis of cells from $500 \mathrm{~h}$ old cultures (217 generations at $D=0.3 \mathrm{~h}^{-1}$ ) has shown massive upregulation of proteins belonging to the $\mathrm{mgl}$ and $\mathrm{mal}$ operons (Wick et al., 2001). No indications for changes other than these triggering increased glucose uptake were found, whereas proteomic studies of clones isolated from an older glucose-limited culture $\left(0 \cdot 2 \mathrm{~h}^{-1}, 773\right.$ generations, $2667 \mathrm{~h}$ ) suggested that mutations with pleiotropic effects had taken place (Kurlandzka et al., 1991). Comparison of the above-mentioned studies and the data presented here suggest that during the first $500 \mathrm{~h}$ in glucose-limited chemostats the growth of E. coli cells is single-nutrient limited and the evolution is indeed driven by improving the Monod parameters. Therefore, experimental determination of these parameters is a good tool to monitor the evolution of the population during this initial time period. After about $500 \mathrm{~h}$, when the potential for optimizing Monod parameters has been exploited, other mutational events such as those reported by Adams and co-workers may take place 
(Kurlandzka et al., 1991; Rosenzweig et al., 1994; Treves et al., 1998), complicating further monitoring of the evolutionary process.

\section{ACKNOWLEDGEMENTS}

We thank Paolo Landini for helpful discussions and for supply of the strain E. coli MV2792, Thomas Ferenci and Uwe Sauer for constructive comments on an earlier version of this manuscript, Peter Reichert for help in the statistical analysis of the data, and A. J. B. Zehnder for support throughout this study. We acknowledge the financial support of this research by a grant from the Swiss National Science Foundation (Grant number 31-50885.97).

\section{REFERENCES}

Atwood, K. C., Schneider, L. K. \& Ryan, F. J. (1951). Selective mechanisms in bacteria. Cold Spring Harbor Symp Quant Biol 16, 345-355.

Ayala, F. J. (2000). Neutralism and selectionism: the molecular clock. Gene 261, 27-33.

Death, A. \& Ferenci, T. (1994). Between feast and famine: endogenous inducer synthesis in the adaptation of Escherichia coli to growth with limiting carbohydrates. J Bacteriol 176, 5101-5107.

Dykhuizen, D. E. (1990). Experimental studies of natural selection in bacteria. Annu Rev Ecol Syst 21, 373-398.

Dykhuizen, D. \& Hartl, D. (1981). Evolution of competitive ability in Escherichia coli. Evolution 35, 581-594.

Dykhuizen, D. E. \& Hartl, D. L. (1983). Selection in chemostats. Microbiol Rev 47, 150-168.

Eisenthal, R. \& Cornish-Bowden, A. (1974). The direct linear plot: a new graphical procedure for estimating enzyme kinetic parameters. Biochem J 139, 715-720.

Ferenci, T. (1996). Adaptation to life at micromolar nutrient levels: the regulation of Escherichia coli glucose transport by endoinduction and cAMP. FEMS Microbiol Rev 18, 301-317.

Ferenci, T. (1999). 'Growth of bacterial cultures' 50 years on: towards an uncertainty principle instead of constants in bacterial growth kinetics. Res Microbiol 150, 431-438.

Finkel, S. E., Zinser, E., Gupta, S. \& Kolter, R. (1998). Life and death in stationary phase. In Molecular Microbiology, pp. 3-16. Edited by S. J. W. Busby, M. C. Thomas \& N. L. Brown. Berlin: Springer.

Hartl, D. \& Dykhuizen, D. (1979). A selectively driven molecular clock. Nature 281, 230-231.

Kimura, M. (1983). The Neutral Theory of Molecular Evolution. Cambridge: Cambridge University Press.

Kovářová, K. (1996). Growth kinetics of Escherichia coli: effect of temperature, mixed substrate utilization, and adaptation to carbon-limited growth. PhD thesis, ETH Zürich.

Kovářová, K., Zehnder, A. J. B. \& Egli, T. (1996). Temperature dependent growth kinetics of Escherichia coli ML 30 in glucoselimited continuous culture. J Bacteriol 178, 4530-4539.

Kovářová-Kovar, K. \& Egli, T. (1998). Growth kinetics of suspended microbial cells: from single-substrate-controlled growth to mixed-substrate kinetics. Microbiol Mol Biol Rev 62, 646-666.

Kubitschek, H. E. (1974). Operation of selection pressure on microbial populations. In Evolution in the Microbial World
(Society for General Microbiology Symposium no. 24), pp. 105-130. Edited by M. J. Carlile and J. J. Skehel. Cambridge: Cambridge University Press.

Kubitschek, H. E. \& Bendigkeit, H. E. (1964). Mutation in continuous cultures. I. Dependence of mutational response upon growth-limiting factors. Mutation Res 1, 113-120.

Kurlandzka, A., Rosenzweig, R. F. \& Adams, J. (1991). Identification of adaptive changes in an evolving population of Escherichia coli: the role of changes with regulatory and highly pleiotropic effects. Mol Biol Evol 8, 261-281.

Lange, R. \& Hengge-Aronis, R. (1994). The cellular concentration of the $\sigma^{\mathrm{s}}$ subunit of RNA polymerase in Escherichia coli is controlled at the levels of transcription, translation, and protein stability. Genes Dev 8, 1600-1612.

Merrel, D. J. (1981). Ecological Genetics. Minneapolis : University of Minnesota Press.

Miller, J. H. (1972). Experiments in Molecular Genetics. Cold Spring Harbor, NY: Cold Spring Harbor Laboratory Press.

Monod, J. (1942). Recherche sur la Croissance des Cultures Bactériennes. Paris: Hermann et Cie.

Notley, L. \& Ferenci, T. (1996). Induction of RpoS-dependent functions in glucose-limited continuous culture: what level of nutrient limitation induces the stationary phase of Escherichia coli. J Bacteriol 178, 1465-1468.

Notley-McRobb, L. \& Ferenci, T. (1999a). Adaptive $m g l$-regulatory mutations and genetic diversity evolving in glucose-limited Escherichia coli populations. Environ Microbiol 1, 33-43.

Notley-McRobb, L. \& Ferenci, T. (1999b). The generation of multiple co-existing mal-regulatory mutations through polygenic evolution in glucose-limited populations of Escherichia coli. Environ Microbiol 1, 45-52.

Notley-McRobb, L. \& Ferenci, T. (2000). Experimental analysis of molecular events during mutational periodic selections in bacterial evolution. Genetics 156, 1493-1501.

Novick, A. \& Szilard, L. (1950). Experiments with the chemostat on spontaneous mutations of bacteria. Genetics 36, 708-719.

Pirt, S. J. (1965). The maintenance energy of bacteria in growing cultures. Proc R Soc Lond B Biol Sci 163, 224-231.

Powell, E. O. (1958). Criteria for growth of contaminants and mutants in continuous culture. J Gen Microbiol 18, 259-268.

Powell, E. O. (1967). The growth rate of micro-organisms as function of substrate concentration. In Microbial Physiology and Continuous Culture, pp. 34-55. Edited by C. G. T. Evans, R. E. Strange \& D. W. Tempest. London: HMSO.

Reichert, P. (1994). AQUASIM - a tool for simulation and data analysis of aquatic systems. Water Sci Technol 30, 21-30.

Rosenzweig, R., Sharp, R., Treves, D. \& Adams, J. (1994). Microbial evolution in a simple unstructured environment: genetic differentiation in Escherichia coli. Genetics 137, 903-917.

Sak, B. D., Eisenstark, A. \& Touati, D. (1989). Exonuclease III and the catalase hydroperoxidase II in Escherichia coli are both regulated by the katF gene product. Proc Natl Acad Sci US A 86, 3271-3275.

Savva, D. (1982). Spontaneous mutation rates in continuous cultures: the effect of some environmental factors. Microbios 33, 81-92.

Senn, H., Lendenmann, U., Snozzi, M., Hamer, G. \& Egli, T. (1994). The growth of Escherichia coli in glucose-limited chemostat cultures: a re-examination of the kinetics. Biochim Biophys Acta 1201, 424-436.

Shehata, T. E. \& Marr, A. G. (1971). Effect of nutrient con- 
centration on the growth of Escherichia coli. J Bacteriol 107, 210-216.

Smith, K. C. (1992). Spontaneous mutagenesis: experimental, genetic and other factors. Mutat Res 277, 139-162.

Treves, D., Manning, S. \& Adams, J. (1998). Repeated evolution of an acetate-crossfeeding polymorphism in long-term populations of Escherichia coli. Mol Biol Evol 15, 789-797.

Veldkamp, H. \& Jannasch, H. W. (1972). Mixed culture studies with the chemostat. J Appl Chem Biotechnol 22, 105-123.

Volkert, M. R., Hajec, L. I., Matijasevic, Z., Fang, F. C. \& Prince, R. (1994). Induction of the Escherichia coli aidB gene under oxygenlimiting conditions requires a functional $r p o S(k a t F)$ gene. $J$ Bacteriol 176, 7638-7645.

Wahl, L. M. \& Krakauer, D. C. (2000). Models of experimental evolution: the role of genetic chance and selective necessity. Genetics 156, 1437-1448.

Westerhoff, H. V., Lolkema, J. S., Otto, R. \& Hellingwerf, K. J.
(1982). Thermodynamics of growth, non-equilibrium thermodynamics of bacterial growth, the phenomenological and the mosaic approach. Biochim Biophys Acta 683, 181-220.

Wick, L. M., Quadroni, M. \& Egli, T. (2001). Short- and long-term changes in proteome composition and kinetic properties in a culture of Escherichia coli during transition from glucose-excess to glucose-limited growth conditions in continuous culture and vice versa. Environ Microbiol 3, 588-599.

Zambrano, M. M., Siegele, D. A., Almiron, M., Tormo, A. \& Kolter, R. (1993). Microbial competition: Escherichia coli mutants that take over stationary phase cultures. Science 259, 1757-1760.

Zuckerkandl, E. \& Pauling, L. (1965). Evolutionary divergence and convergence in proteins. In Evolving Genes and Proteins, pp. 97-166. Edited by V. Bryson \& H. J. Vogel. New York: Academic Press.

Received 21 March 2002; revised 27 May 2002; accepted 30 May 2002. 